\title{
Towards Improving Energy Efficiency Regulations of Bulk Carriers
}

\author{
Ivica Ančić ${ }^{* 1}$, Gerasimos Theotokatos ${ }^{2}$, Nikola Vladimir ${ }^{1}$ \\ ${ }^{1}$ University of Zagreb, Faculty of Mechanical Engineering and Naval Architecture, \\ Zagreb, Croatia, ivica.ancic@fsb.hr \\ ${ }^{2}$ University of Strathclyde, Department of Naval Architecture, Ocean and Marine \\ Engineering, Maritime Safety Research Centre, Henry Dyer Building, 100 Montrose \\ Street, Glasgow, G4 OLZ, United Kingdom
}

\begin{abstract}
The introduction of the Energy Efficiency Design Index (EEDI) by the International Maritime Organization (IMO) caused an upsurge in activities for increasing the energy efficiency and reducing $\mathrm{CO}_{2}$ emissions of new vessel designs. However, application of the EEDI is not expected to further advance future design improvements partly owing to the fact the majority of the newbuildings already comply with EEDI requirements and particularly since EEDI only considers a single operating point. In addition, the EEDI does not effectively assess a realistic improvement of measures for increasing the ship operating energy efficiency as they can be quite effective in the considered operating point for the EEDI but their performance greatly varies in the real operating conditions. In this study, a more realistic definition of the EEDI is proposed, which is based on a number of representative vessel operating points. The application of the proposed approach for the case of bulk carriers is investigated and the results are discussed in order to reveal its advantages against the currently used approach. The proposed approach can be employed by IMO for improving the energy efficiency regulatory framework.
\end{abstract}

Keywords: EEDI, energy efficiency, bulk carriers, $\mathrm{CO}_{2}$ emission, EEDI reference surface 


\section{INTRODUCTION}

The International Maritime Organization (IMO) has adopted new regulation on energy efficiency for ships (MEPC, 2011a) according to which, the International Energy Efficiency (IEE) Certificate should be issued for every ship. In order to obtain it, the ship has to comply with the Energy Efficiency Design Index (EEDI) and the Ship Energy Efficiency Management Plan (SEEMP) requirements. The EEDI is a technical measure and requires that for every new ship of 400 GT and above, the Attained EEDI has to be calculated (MEPC, 2014) and not exceed the Required EEDI, which is defined by the EEDI reference line value and an appropriate reduction factor. The EEDI reference line value is a function of the ship type and its capacity (MEPC, 2013). The reduction factor is defined in a set of time intervals, roughly $10 \%$ reduction every 5 years (MEPC, 2011). The EEDI reference line values should represent the average ship energy efficiency of current fleet, whilst the reduction factor should represent a requirement for new ships to improve their energy efficiency compared to the status of the current fleet. SEEMP is an operational measure to increase ship energy efficiency and is also compulsory to every ship of $400 \mathrm{GT}$ and above.

The introduction of the EEDI and the SEEMP has the noteworthy aim, as recognized in the preamble of MEPC (2011a), to improve the energy efficiency for ships through a set of technical performance standards, which would result in reduction of emissions of any substances that originate from fuel and its combustion process, including those already controlled by Annex VI. These policies as well as policies aiming to improve the implementation of energy efficiency in shipping need to be carefully considered in order to ensure energy efficiency improvements whilst avoiding unnecessary burden on the shipping industry with ineffective regulation through technical, operational or market-based measures, as pointed out by Rehmatulla and Smith (2015). This is particularly pronounced in the definition of the reduction factor, as thoroughly investigated by Ančić and Šestan (2015). They concluded that the reduction factor seems to be rigidly set and is likely to be either too lenient or too strict for the new ships, and proposed an alternative requirement that would allow for a feedback from the market and that is more likely to stimulate the improvements in energy efficiency and the $\mathrm{CO}_{2}$ emission reduction. Feedback from the market is particularly important as many parameters could influence the energy efficiency of new ships. For example, sailing at lower speeds proved to have a significant impact on the fuel consumption and directly on the $\mathrm{CO}_{2}$ emission (Lindstad et al., 2011), so it seems reasonable to include ship speed in the Required EEDI definition. Similar remarks were given 
by Simic (2014) who analysed the energy efficiency of inland waterway ships and identified a strong

influence of the ship speed on the EEDI value. In addition, some externalities could indirectly lead to the GHG emission reduction. For example, Lindstad et al. (2013) assessed the impact of the Panama Canal expansion on the new bulk carriers design and concluded that the fuel consumption saving by up to $15-25 \%$ could be possible at negative abatement cost. The current approach set by the EEDI is insensitive to such occurrences.

Special consideration should be given to innovative energy efficient technologies. The abatement cost and cost effectiveness of these technologies are analysed in detail by MEPC (2011b). It is concluded that these technologies have a potential to significantly reduce the $\mathrm{CO}_{2}$ emission from ships, but there are many barriers in their implementation, even though many of them seem to be cost effective. It has to be pointed out that these technologies have the potential to further reduce not only GHG emission, but also other harmful substances emission. Dedes et al. (2012) investigated possibilities of implementing energy storage devices on-board bulk carriers. They found that a Power Take-Off/Power Take-In (PTO/PTI) system with batteries could save fuel and reduce harmful substances emissions, especially for Panamax and Handysize bulk carriers. It is even proved to be economically feasible, although for a relatively high fuel price (520 USD/tonne). Mäkiharju et al. (2012) analysed the cost effectiveness of an air lubrication system, whilst Butterworth et al. (2015) performed the experimental analysis of implementing air cavity concept on a container ship model. Both technologies lead to the drag reduction, even though their influence is less pronounced at higher speeds. The implementation of a twisted rudder on a container ship provided greater performance driven by increased hull efficiency due to lesser thrust deduction fraction and more effective wake fraction as well as the decreased propeller rotating speed (Kim et al., 2014). Other technologies, referred as Carbon dioxide Reduction Technologies (CRT) have also been considered by Calleya et al. (2015) and found to have potential to reduce the $\mathrm{CO}_{2}$ emissions.

Not only alternative technologies, but also alternative fuels and renewable power sources could lead to the reduction of the $\mathrm{CO}_{2}$ emissions. Bengston et al. (2012) performed an analysis of two pathways: first leading from heavy fuel oil (HFO) to marine diesel oil (MDO) and then to biodiesel, and the other leading from HFO to liquefied natural gas (LNG) and then to biogas. Both pathways lead to the reduction of the $\mathrm{CO}_{2}$ emission, but a detailed life cycle analysis of a ro-ro passenger ship engaged in short-sea shipping revealed that the use of biofuels can increase the eutrophication potential (EP). 
This emphasizes the importance of a detailed analysis in order to accurately estimate the environmental impact of a ship, which is especially important for ships employed in short-sea shipping. The pollution originated from these ships is especially pernicious for public health, since it occurs mostly in and near ports and highly populated areas, as highlighted by Runko Luttenberger et al. (2013). In that sense, the use of LNG offers significant advantages as it reduces the emission of local pollutants substantially below all current and proposed emissions standards for marine diesel engines and does not increase $\mathrm{NO}_{x}$ emissions (Livanos et al. 2014; Thomson et al., 2015). A study on the implementation of renewable power sources on ro-ro passenger vessels revealed that they have significant impact on the $\mathrm{CO}_{2}$ emissions, but rather negligible impact on the EEDI (Ancic et al, 2014).

Apart from technical and operational measures, there has been a discussion about market-based measures (MBM). A feasibility study and impact assessment of introducing MBMs on a global scale has been performed by MEPC (2010). A similar study by Miola et al. (2011) was focused on the EU region. Both studies concluded that the MBMs have a significant abatement potential, even though there are also significant barriers and challenges, which are more pronounced in cases they are implemented on a regional basis.

Ekanem Attah and Bucknall (2015) investigated the impact of the EEDI on LNG carriers and concluded that the current EEDI reference baseline is insufficient to stimulate improvements in their energy efficiency, as the recently proposed ship designs with dual fuel (DF) engines already satisfy the EEDI regulations requirements. However, when considering the methane slip, they concluded that the GHG emissions could potentially increase by up to $115 \%$. Hence, a modification of the EEDI formulation is required, which was partly recognised by MEPC (MEPC, 2011).

With the introduction of the EEDI requirements, the review of the status of technological developments was also planned aiming to assess the influence of new technologies on the EEDI. If proven necessary, the EEDI regulation requirements including the time periods, the EEDI reference line parameters for relevant ship types and the reduction rates will be amended by the MEPC. The review was planned in two stages, the first at the beginning of phase 1 (1 January 2015), whereas the second at the midpoint of phase 2 ( 1 July 2022). The results of the first review process were presented at a recent MEPC session (MEPC, 2016). The majority of bulk carriers (57\%) built during Phase 0 already meet phase 2 requirements. However, bulk carriers smaller than 40,000 DWT and larger than 75,000 DWT do not on average meet phase 2 requirements. This report does not provide explanation on why 
some ships meet the requirements whereas others do not. Although suggestions to increase the phase 2 reduction rate to $25 \%$ for bulk carriers were discussed, this was not implemented, partly due to political pressure reasons, and partly due to the lack of the sufficient data.

The aim of this work is to propose an innovative approach in the EEDI definition for bulk carriers, with particular objective to provide a fair basis for the comparison of the energy efficiency of different bulk carriers and encourage the application of innovative energy efficient technologies.

There are three main challenges in the EEDI definition: the first one is to evaluate the ship energy efficiency, the second is to compare different ships in order to rate their energy efficiency (performance) and the third is to set the benchmark that every new ship has to comply with.

The first challenge is addressed in section 2.1 through the analysis of the current approach for assessing the ship energy efficiency performance by using the Attained EEDI. Based on the conclusions from this analysis, a new methodology for the Attained EEDI calculation is proposed that ensures a corrected and more realistic assessment of the ship energy efficiency.

The second challenge is addressed in section 2.2 through analysing the current approach used to define the Required EEDI. This approach also tackles with special emphasis the consequences of defining the EEDI reference line value solely by using the ship capacity. A new approach that defines the EEDI reference surface based on the ship capacity and design speed is proposed. The methodology that employs the coefficient of determination used to determine how well the proposed function describes a defined set of data is also outlined.

The third challenge requires the analysis of the EEDI reduction factor definition. This was addressed in detail in Ančić and Šestan (2015) and thus, it will not be discussed herein.

The results of the proposed methodology along with their comparison with the current approach are presented in section 3. A thorough discussion follows in section 4 pointing out the pros and cons of the two approaches. Finally, the concluding remarks along with guidelines for further research and policy implications are reported. 


\section{METHODS}

\subsection{Attained EEDI calculation}

According to MEPC (2014), the attained EEDI is calculated according to the following equation:

$$
\begin{aligned}
\text { Attained EEDI } & =\frac{\left(\prod_{j=1}^{M} f_{j}\right)\left(\sum_{i=1}^{n M E} P_{M E(i)} \cdot C_{F M E(i)} \cdot S F C_{M E(i)}\right)+\left(P_{A E} \cdot C_{F A E} \cdot S F C_{A E^{*}}\right)}{f_{i} \cdot f_{c} \cdot f_{l} \cdot \operatorname{Capacity} \cdot f_{w} \cdot V_{r e f}}+ \\
& +\frac{\left(\left(\prod_{j=1}^{M} f_{j} \cdot \sum_{i=1}^{n P T I} P_{P T I(i)}-\sum_{i=1}^{n e f f} f_{e f f(i)} \cdot P_{A E E f f(i)}\right) C_{F A E} \cdot S F C_{A E}\right)-\left(\sum_{i=1}^{n e f f} f_{e f(i)} \cdot P_{e f f(i)} \cdot C_{F M E} \cdot S F C_{M E^{* *}}\right)}{f_{i} \cdot f_{c} \cdot f_{l} \cdot \operatorname{Capacity} \cdot f_{w} \cdot V_{r e f}}
\end{aligned}
$$

The symbols in this formula are described in detail in MEPC (2014).

It has to be emphasized that the EEDI was introduced as a design index that should reflect the design of the ship. Because of that, MEPC accepted the EEDI calculation at $75 \%$ MCR of main engine(s), full load vessel capacity and calm sea with no wind and waves. A more appropriate measure corresponding to the energy efficiency of a ship in operation is the Energy Efficiency Operational Indicator (EEOI). However, it must be noted that as ships are designed for operation, the design conditions, in which the EEDI is calculated, should correspond to or at least approximate the vessel actual operating conditions. An approach for comparing the life cycle performance and emissions of ships based on reference operating profiles was also proposed in Cichowicz et al. (2015) as an alternative to the EEDI metrics. In addition, alternative metrics to EEDI that can be used in voluntary basis are reported in Blanco-Davis and Zhou (2016). They concluded that a life cycle assessment can be used in parallel to the regulatory metrics.

A similar approach is currently used in the $\mathrm{NO}_{x}$ technical code (MEPC, 2008), according to which the marine engines are tested at various combinations of loads and speeds, depending on the application (propulsion or auxiliary engines). The $\mathrm{NO}_{\mathrm{x}}$ emissions are measured at each operating point and weighting factors are used to obtain the average $\mathrm{NO}_{\mathrm{x}}$ emission, which subsequently needs to comply with the limits set according to Tier II or III.

The current approach for calculating the Attained EEDI could also be formulated in the same way considering the weighting factor for the operating point of $75 \%$ MCR equal to 1 , whereas for every other main engine operating point, the weighting factors are equal to 0 . Such an operating scenario cannot be considered either realistic or representative for a ship in operation. However, the difficulty of 
accounting or reflecting the actual ship operating profile on the EEDI calculation during the ship design phase must be acknowledged as it is impossible to predict each condition which the ship might encounter in her lifetime.

According to Banks et al. (2013) bulk carriers in average in 2011 spent $41 \%$ of their operational time sailing loaded, $32 \%$ sailing in ballast condition and $27 \%$ in port. It is also very interesting to observe the speed profile of bulk carriers in laden and ballast conditions. For laden voyages, their average speed was around 12 knots in 2011, and around 13 knots in 2009. For ballast voyages, the respective average speed values were a bit higher, around 13.5 knots in 2011 and 14.5 knots in 2009. The values observed in 2009 roughly correspond to $75 \%$ of MCR both in fully loaded and in ballast conditions as prescribed by MEPC (2014) in the EEDI calculation. Due to the market situation, the voluntary slow steaming was introduced and as a result lower speeds were used in 2011. But much more interesting in this analysis is to observe the entire speed profile, rather than average speeds only. The analysis of measured data reported by Banks et al. (2013) reveals that the investigated ships spent roughly $50 \%$ of their operation sailing at speeds which correspond to engine load around $75 \%$ of MCR, i.e. between 12.5 and 13.5 knots. In addition, they sailed around $10 \%$ of their operation at speeds of 14 knots and higher (corresponding to engine load of $100 \% \mathrm{MCR}$ ), they spent around $30 \%$ of their operation sailing between 11 and 12 knots (corresponding to engine load around $50 \%$ MCR) and roughly $10 \%$ of their operation sailing at lower speeds (corresponding to lower engine loads around 10\% MCR). These figures are summarized in Table 1.

Table 1 Weighting factors for various main engine operating loads for bulk carriers

By observing the data presented in Table 1, several conclusions can be drawn. First, the market situation has a high impact on the operational profile of ships. Second, the weighting factors prescribed by MEPC (2008) in the $\mathrm{NO}_{\mathrm{x}}$ technical code E3 cycle roughly correspond to the observed operating profile for 2009. Third, the approach used for the EEDI calculation does not correspond to any operational profile; not even slightly. Based on the preceding analysis, it is concluded that the ship operational conditions, described by main engine load and ship sailing conditions, could be approximated using the data reported in Table 2. 
Table 2 Engine and ship loading frequencies of occurrences for bulk carriers in operation

From Table 2, it can be observed that the current approach used in the EEDI calculation (i.e. engine load at $75 \%$ of MCR and full ship load condition) corresponds to $20 \%$ of the bulk carriers operational time $\left(f_{751}=0.2\right)$. Since the EEDI is currently defined in tons of $\mathrm{CO}_{2}$ per ton and nautical mile of cargo transported, it is not possible to calculate it considering the ship sailing in ballast or the ship port operation. Therefore, it is proposed in this work to calculate the Attained EEDI for a ship as the $\mathrm{CO}_{2}$ emission in $\mathrm{g} \mathrm{CO}_{2}$ per hour, which would correspond to ship speed and capacity. If correction factors and innovative technologies are omitted, the formula for calculating the Attained EEDI for each operating condition yields:

$$
\begin{aligned}
& \text { Attained } E E D I_{x y}=\sum_{i=1}^{n M E} C O 2_{M E(i), x y}+\sum_{i=1}^{n A E} C O 2_{A E(i), x y} \\
& =\sum_{i=1}^{M M E} P_{M E(i), x y} \cdot C_{F M E(i)} \cdot S F C_{M E(i), x y}+\sum_{i=1}^{n A E} P_{A E, x y} \cdot C_{F A E} \cdot S F C_{A E \cdot, x y}
\end{aligned}
$$

where $x$ corresponds to different main engine loads, $y$ corresponds to different ship operating conditions, whilst $M E$ denotes main engine(s) and $A E$ auxiliary engine(s). $C O 2$ represents $\mathrm{CO}_{2}$ emissions of ship engines $\left(\mathrm{g} \mathrm{CO}_{2} / \mathrm{h}\right)$ as reported in the $\mathrm{NO}_{x}$ technical code. Alternatively, if data is not available, the $\mathrm{CO}_{2}$ emission can be calculated based on the engine power $P(\mathrm{~kW})$, specific fuel consumption SFC (g fuel/kWh) and the conversion factor $C_{F}\left(\mathrm{~g} \mathrm{CO}_{2} / \mathrm{g}\right.$ fuel). By taking into account the frequencies of occurrences from Table 2 and the values of the Attained EEDI in each operating condition, it is possible to define the average Attained EEDI by using the following equation:

$$
\text { Attained EEDI }=\sum_{x=100,75,50,25,0}^{y=I, b y} f_{x y} \cdot \text { Attained EEDI } I_{x y}
$$

The Attained EEDI defined by eq. (3) corresponds to the average ship $\mathrm{CO}_{2}$ emissions per hour of ship operation. In this case it is necessary also to recalculate the Required EEDI (and the Reference EEDI) in a similar way, since the ship capacity and the design speed affects the attained EEDI (e.g. the bigger and faster ships will have higher Attained EEDI). The Required EEDI must be dependent on both the ship speed and operating condition, and therefore the EEDI reference surface concept has to be introduced. 


\subsection{Required EEDI calculation}

To define the EEDI reference surface as a function of ship speed and operating condition, first the EEDI reference line should be recalculated in order to confirm the validity of the database and the methodology used. Subsequently, the reference line will be updated using new data taking into account the ships delivered in the last 15 years, and the same data set will also be used to define the EEDI reference surface. The correlation between the regression curve (or surface) and the Estimated EEDI values will be determined by using the coefficient of determination $\left(R^{2}\right)$.

\subsubsection{Current MEPC approach}

The current approach according to MEPC (2013) defines the Required EEDI based on the EEDI reference line value, which is calculated as a function of the ship type and capacity, and on the reduction factor $X$, which is defined in a set of time intervals. The EEDI reference line should represent an average EEDI for a ship of certain size and type. The reference line is dependent on ship capacity, according to the following equation:

Estimated EEDI $=\frac{3.1144\left(190 \cdot \sum_{i=1}^{n M E} P_{M E i}+215 \cdot P_{A E}\right)}{\text { Capacity } \cdot V_{\text {ref }}}$

The parameters $a$ and $c$ are obtained from a regression analysis using the least square method. For bulk carriers, the adopted values are $a=961.79$ and $c=-0.477$. In order to validate the used data set, the EEDI reference line calculation is repeated taking into account the guidelines of MEPC (2013). Provided that there is no significant deviation between the calculated and the adopted values of the parameters $a$ and $c$, it can be concluded that the data and the methodology used are consistent with the adopted ones by MEPC. According to the MEPC guidelines, a methodology and a set of criteria are defined as shown in Table 3. These criteria determine which ships will be used for the EEDI reference line calculation. The EEDI reference line will be updated using the data for ships delivered in the last 15 years, from 15 August 2000 to 15 August 2015.

Table 3 Criteria to determine which bulk carriers are used for the EEDI reference line calculation 
The IHS Fairplay Database (formerly known as World Register Of Ships (WROS) database) contains 2,716 ships which meet criteria listed in Table 3 . For some of these ships, data related to engine power, speed and/or capacity misses in the WROS database; therefore 61 ships were excluded. Thus, a total of 2,655 bulk carriers are used for the repeated calculation of the EEDI reference line in this study. When observing the period of the last 15 years, a significantly greater number of ships were delivered. In total, there is data for 8,253 bulk carriers in the WROS database, which meet the criteria set in Table 3. To calculate the EEDI reference line, the Estimated EEDI for every ship has to be calculated. The Estimated EEDI is calculated using the following expression:

Estimated EEDI $=\frac{3.1144\left(190 \cdot \sum_{i=1}^{n M E} P_{M E i}+215 \cdot P_{A E}\right)}{\text { Capacity } \cdot V_{\text {ref }}}$

where Capacity indicates the ship capacity measured in tons of deadweight, $V_{\text {ref }}$ is the ship reference speed in knots according to WROS database, $P_{M E}$ denotes the main engine power in $\mathrm{kW}$ defined as the $75 \%$ of the main engine MCR point, and $P_{A E}$ denotes the auxiliary engine power in kW defined by using the following equations:

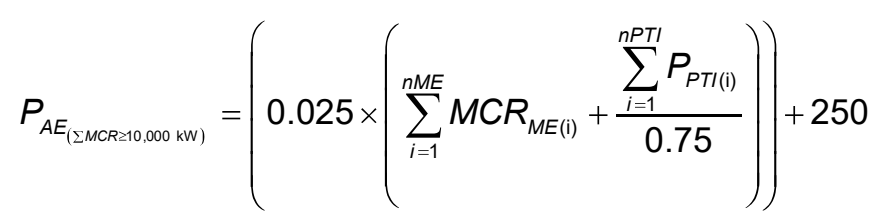

$$
\begin{aligned}
& P_{A E_{(2 M C R A 10,000 \mathrm{KN})}}=\left(0.05 \times\left(\sum_{i=1}^{n M E} M C R_{M E(i)}+\frac{\sum_{i=1}^{n P T I} P_{P T(1)}}{0.75}\right)\right)
\end{aligned}
$$

where $P_{P T I}$ is the $75 \%$ of the rated power consumption of each shaft motor. For the calculation of the Estimated EEDI $P_{P T I}$ is considered to be 0 .

In equation (5) it is assumed (for the reference line calculation) that all ships use HFO, hence instead of $C_{F}$, a value $3.1144 \mathrm{~g} \mathrm{CO}_{2} / \mathrm{g}$ fuel is used, the main engine SFC was considered to be $190 \mathrm{~g} / \mathrm{kWh}$, whilst the auxiliary engine SFC was assumed to be $215 \mathrm{~g} / \mathrm{kWh}$. After calculating the Estimated EEDI values for each ship, the values of parameters $a$ and $c$ are determined using the least square method. Then the input data (Estimated EEDI values) for the calculation of the reference line is filtered through a process according to which, the Estimated EEDI values deviating more than two standard deviations 
from the EEDI reference line are discarded. The regression is then applied again to generate corrected values of the parameters $a$ and $c$.

\subsubsection{Proposed approach}

In order to improve the current approach, the usage of the vessel design speed as an additional depending parameter is proposed. This will convert the EEDI reference line into the EEDI reference surface. The methodology in the proposed approach is similar to the current approach, but based on the proposed definition of the Attained EEDI. The Estimated EEDI will similarly correspond to the $\mathrm{CO}_{2}$ emission of the ship in different operating conditions:

$$
\text { Estimated EEDI } x y=3.1144\left(S F C_{x y} \cdot \sum_{i=1}^{n M E} P_{M E i, x y}+S F C_{x y} \cdot P_{A E, x y}\right)
$$

The average value of the Estimated EEDI can then be calculated by considering weighting factors according to the following equation:

$$
\text { Estimated } E E D I=\sum_{x=100,75,50,25}^{y=l, b, p} f_{x y} \cdot \text { Estimated } E E D I_{x y}
$$

where $P_{M E}$ is the main engine power in $\mathrm{kW}$ defined at $x \%$ of main engine MCR, $P_{A E}$ is the auxiliary engine power in kW as defined by equations (6) and (7), and SFC is the specific fuel consumption in $\mathrm{g} / \mathrm{kWh}$ according to engine type and load. Indexes $x$ and $y$ correspond to different engine loads and different ship operating conditions, respectively, as described in the previous section. On the contrary to the current approach, in the proposed approach the SFC is not considered to be constant for main engines, but is dependent on engine type and load, according to the data listed in Table 4.

Table 4 SFC values for different engine type and load (Baldi et al, 2015, Guan et al, 2014)

In order to calculate the EEDI reference surface, the following different sets of input data can be used.

1. Every recorded ship operating point considering combinations of ship speed, cargo capacity, operating mode (laden, ballast and port), main engine load and auxiliary engines load; 
2. Only recorded ship operating points at full laden and ballast conditions (port staying mode was not taken into account) considering combinations of main engine load and auxiliary engine load;

3. Only recorded full laden conditions;

4. Only average values of the Estimated EEDI are calculated and plotted the design speed and full capacity of the ship.

For the case where every ship operating point is recorded and used in the Estimated EEDI calculation, a definition on how to include the Estimated EEDI values for ships sailing in ballast condition $($ Capacity $=0)$ and for ships staying at port $\left(v_{r e f}=0\right)$ is required. Ships in port have significantly lower power consumption as the main engine does not operate, hence their Estimated EEDI will also be lower compared to full laden and ballast conditions. As in the port mode the ship speed is 0 , the values of the Estimated EEDI representing the port operation will lay in the plane corresponding to $v_{\text {ref }}=0$ and their approximation can be essentially form a single curve similarly to the current approach. As the bulk carrier ships stay in average around $30 \%$ of their operating time in ports, this mode contribution on $\mathrm{CO}_{2}$ emissions must not be neglected. However, it is not reasonable to include them in the same EEDI reference surface. Therefore a separate surface is introduced herein to evaluate the ships energy efficiency in ports.

Similarly for ships sailing in ballast condition, their Estimated EEDI values should be plotted against the corresponding ship speed at the Capacity $=0$. This will again generate a huge number of points in the plane corresponding to zero capacity, which cannot be easily approximated as EEDI values depend on the ship size (bigger ship will have higher EEDI even when sailing in ballast). Therefore, another reference surface is proposed to be introduced for evaluating ships energy efficiency in ballast condition. For this surface, it is assumed that, when sailing in ballast, ships can achieve $15 \%$ higher speed for the same engine load.

In order to determine the EEDI dependency on the ship speed and capacity, a non-dimensional analysis has to be performed by considering the following relations:

$P \approx v^{3} \cdot S$

$S \approx L^{2} \approx D W T^{2 / 3}$ 
where $S$ is the ship wetted surface, and $L$ is the ship length.

Combining eq. (2), (10) and (11), assuming that the SFC and $C_{F}$ are constant and neglecting the auxiliary engine power (or assuming its linear dependence on the main engine power), the following relation can be derived:

$E E D I \approx P \approx v^{3} \cdot S \approx v^{3} \cdot D W T^{2 / 3}$

Thus, the function describing the EEDI reference surface that is dependent on the ship speed and capacity can be considered to be described by the following equation:

EEDI reference surface value $=a \cdot D W T^{b} \cdot v^{c}+d$

where parameters $a, b, c$ and $d$ are determined by the regression analysis as described in the current approach. According to eq. (12), the expected values of the parameters $b$ and $c$ are $2 / 3$ and is 3 , respectively. The value of the parameter $d$ should be positive and account for the auxiliary engines $\mathrm{CO}_{2}$ emissions.

As in the current approach, the input data is filtered through a process where values of Estimated EEDI deviating more than two standard deviations from the EEDI reference surface are discarded, and subsequently the values of parameters $a, b, c$ and $d$ are recalculated.

\subsubsection{Standard deviation and coefficient of determination}

Since the methodology to calculate the standard deviation $(S D)$ and the coefficient of determination $\left(R^{2}\right)$ for the EEDI reference line prescribed by MEPC (2013) is not presented in any of the MEPC documents (to the authors knowledge), the following methodology has been adopted. The standard deviation can be defined and measured in two different approaches. It can be defined in "absolute" values and measured in the same units as the EEDI using the following equation:

$$
S D=\sqrt{\sum_{i=1}^{n}\left(\frac{\left(y_{i}-f\left(x_{i}\right)\right)^{2}}{n}\right)}
$$

where $i$ denotes the ship $l, y_{i}$ is the actual value of Estimated EEDI for ship $i, f\left(x_{i}\right)$ is the EEDI reference value for ship $i$, and $n$ is the total number of ships.

Alternatively, the standard deviation can also be defined by using the "relative" value and measured in percentage, according to the following equation: 
$S D=\sqrt{\sum_{i=1}^{n}\left(\frac{\left(\frac{y_{i}-f\left(x_{i}\right)}{f\left(x_{i}\right)}\right)^{2}}{n}\right)}$

In the case where the $S D$ is defined as an "absolute" value and has the same unit as the EEDI, it represents the absolute deviation from the proposed EEDI reference line. In the current approach adopted by MEPC, the EEDI depends on ship size, in specific the EEDI is higher for smaller ships, which implies that in the filtering process, generally smaller ships will be discarded, i.e. ships which have the value of their Estimated EEDI higher or lower than a certain number (two values of $S D$ ). In the case where the $S D$ is calculated by using the "relative" value, it would represent a deviation from the EEDI reference line by a certain percentage. In that case, in the filtering process ships which have their Estimated EEDI deviating by a certain percent from the reference value are discarded. This condition, which is a relative measure, applies similarly to every ship regardless of their size. Therefore, this approach with the relative SD is considered to be fair and is used in this work.

The coefficient of determination is used to determine how well the proposed function describes a set of data. The coefficient of determination is defined according to the following equation:

$$
R^{2}=1-\frac{S S_{r e s}}{S S_{\text {tot }}}
$$

where:

$$
\begin{aligned}
& S S_{\text {res }}=\sum_{i=1}^{n}\left(y_{i}-f\left(x_{i}\right)\right)^{2} \\
& S S_{\text {tot }}=\sum_{i=1}^{n}\left(y_{i}-\bar{y}\right)^{2}
\end{aligned}
$$

with $\bar{y}$ denoting the average Estimated EEDI for all bulk carriers considered.

From the definition of eq. (16)-(19), it can be inferred that the coefficient of determination could take the following characteristic values:

- $R^{2}=1$ law; $y_{i}=f\left(x_{i}\right) \forall i \in\{1, n\}$,

- $\quad 0.75<R^{2}<1$ very good correlation, 
- $0.5<R^{2}<0.75$ average correlation,

- $\quad 0.25<R^{2}<0.5$ low correlation,

- $R^{2}<0.25$ no correlation.

These ranges are not strictly defined, but they indicate how appropriate the correlated function is. In some cases, it might even be possible for the coefficient of determination to have a negative value (if $\left.S S_{\text {res }}>S S_{t o t}\right)$. The value of the coefficient of determination will be used to determine how well the reference EEDI describes the energy efficiency of the fleet of bulk carriers.

\section{RESULTS}

The parameters of the EEDI reference line are calculated based on the current MEPC methodology, whereas the parameters of the EEDI reference surface are estimated according to the proposed methodology herein. The derived results for the EEDI reference line for bulk carriers are presented in Figures 1 and 2.

Figure 1 Updated EEDI reference line according to the methodology prescribed by MEPC (2013) for bulk carriers using $S D$ defined in "absolute" value (after correction)

Figure 2 Updated EEDI reference line according to the methodology prescribed by MEPC (2013) for bulk carriers using $S D$ defined in "relative" value (after correction)

The values of the parameters $a$ and $c$ calculated without and with performing filtering, respectively, as well as the values of the coefficients of determination are given in Table 5. It has to be pointed out that the standard deviation both in "absolute" and "relative" values are used in the updated calculation (using ships delivered in the last 15 years). The "absolute" value of $S D$ was found to be $3.2167 \mathrm{~g} \mathrm{CO}_{2} / \mathrm{t} \mathrm{nm}$, whereas the "relative" value was calculated as $15.35 \%$. When using the "absolute" $S D$ approach, 67 ships having the Estimated EEDI deviating by more than $6.4334 \mathrm{~g} \mathrm{CO}_{2} / \mathrm{t} \mathrm{nm}$ from the EEDI reference line value were omitted from the EEDI line calculation. The biggest of them had a deadweight of $32,000 \mathrm{t}$, meaning that this approach discards smaller ships. When using the "relative" SD approach, 226 ships having the Estimated EEDI deviating by more than $30.7 \%$ from the EEDI reference line value were omitted from the EEDI line calculation. The discarded ships capacity was almost evenly distributed within the considered range, indicating that the relative SD approach is not sensitive to the ship capacity. 
Table 5 Values of parameters $a$ and $c$ and the coefficient of determination for the bulk carriers used in the calculation of EEDI reference line

The calculated EEDI reference surfaces for bulk carriers delivered in the last 15 years are presented in Figures 3 and 4 . The derived values of the parameters $a, b, c$ and $d$, as well as the calculated standard deviation and the coefficient of determination are given in Table 6.

Figure 3 EEDI reference surface for bulk carriers using average EEDI

Figure 4 EEDI reference surface for bulk carriers using a set of operating points

Table 6 Values of parameters $a, b, c$ and $d$ for the EEDI reference surface for bulk carriers

\section{DISCUSSION}

From the values of the coefficient of determination presented in the previous section it can be concluded that the proposed approach represents the energy efficiency of the current bulk carrier fleet better than the current MEPC one. There are several reasons for that. The currently used approach, as pointed out in the introduction, observes only one ship operating condition (laden), and only one engine load condition ( $75 \%$ of engine MCR point). By considering the entire ship operational profile, it can be inferred that the operating conditions used by the current EEDI formula is achieved for only approximately $20 \%$ of the ship operating time. It has to be emphasized again that even though the EEDI is determined for the ship design condition, that design condition only reflects and is determined by the expected operational conditions of a ship. This particularly refers to alternative ship power systems, like integrated electric or hybrid power systems, which main characteristic is the centralized production of the ship propulsion and electrical power. Such configurations have the following two main features: lower energy efficiency in one operating point (because of the higher energy conversion losses), but higher energy efficiency over the entire operating profile as only the required generator sets operate with higher efficiency compared to the efficiency that can be obtained by a large engine operating in very low loads. In addition, the integrated power systems generally have 
higher reliability and are more versatile. In the current formula used for the Attained EEDI calculation MEPC (2013), these advantages are not manifested. On the contrary, the conventional power systems turn out to be more energy efficient since only one operating point is considered ( $75 \%$ MCR and laden condition). In this respect, the proposed methodology to define the Attained EEDI is much closer to the real ship operation and hence provides enhanced credibility for evaluating the actual ship energy efficiency.

By including the correction factor for weather conditions $f_{w}$ in eq. (2), EEDI essentially becomes $E E D I_{\text {weather }}$ and can more effectively represent the ship real operating conditions. The $f_{w}$ was introduced in the EEDI formula from the beginning of the EEDI development (MEPC, 2013) with a remark that separate guidelines will be provided for its calculation. There were several attempts within MEPC and by researchers (Bøckmann et Steen, 2016) to develop these guidelines in order to define $f_{w}$ either globally or for some specific region, but it is still not clear which approach is the most appropriate one. However, the proposed approach considers the main engine operating profile, which incorporates the effect of the environmental conditions. Thus, there is no need to use and analyse environmental data (wind, wave, sea state) that include great uncertainty for determining the weather correction factor. The engine operating profile (engine power versus frequency of occurrence) can be easily derived by analysing acquired shaft torque and rotational speed measurements.

Another major drawback of the current MEPC approach is that the reference EEDI is determined only by the ship size. In this respect, the majority of ships with lower design speed satisfy the EEDI requirement, even though they do not have any features or technologies that would significantly increase their energy efficiency. This means that by using the ship design speed reduction, every ship can easily satisfy the EEDI requirement. This can result in the GHG emission reduction, but will not lead to significant improvements to energy efficiency and implementation of innovative energy efficient technologies as proclaimed by the MEPC (2011). On the contrary, this can potentially lead to ship under-powering, which may have as a consequence the safety status deterioration for ships in operation, which in turn, may result in ecological disasters caused by ships colliding or grounding under heavy seas conditions. With the implementation of new technologies or advanced power configurations, both the ship safety and its environmental characteristics can be improved.

The approach proposed herein defines the EEDI reference surface as a function of ship capacity and speed. Therefore, a more realistic and physically justifiable distribution of the EEDI values can be 
obtained as it is derived from the plots presented in Figures 6 and 7. Regardless the considered ships design speed, there are ships with the Estimated EEDI value both above and below the EEDI reference surface. It can be concluded that the proposed approach makes a true distinction between more and less energy efficient ships, whilst the current MEPC approach rather makes a distinction between faster and slower ships.

Another difference between the current and the proposed approaches is that the EEDI in the proposed approach is defined in $\mathrm{g} \mathrm{CO}_{2} / \mathrm{h}$, and not in $\mathrm{g} \mathrm{CO}_{2} / \mathrm{t} \mathrm{nm}$. This of course implies that, according the proposed approach, bigger and faster ships will have higher EEDI. However, this does not pose a problem, since the reference EEDI is a function of ships capacity and speed, so for bigger and faster ships the reference EEDI is also higher. In fact, by using the proposed approach, it is possible to calculate the EEDI for ships not transporting any cargo (in ballast condition), and for ships not sailing (staying in port or at anchorage). This allows for a comparison of ships not only in one design point, as the current MEPC approach requires, but over the entire operating profile thus providing a tool for the holistic estimation of ships energy efficiency. It must be pointed out that the vessel design speed is considered in the current approach as the required EEDI surface is a function of the ship capacity and design speed. Thus, the initial EEDI tool intention, i.e. the limitation of $\mathrm{CO}_{2}$ emissions per transported cargo and sailed distance, is effectively satisfied by considering the proposed approach, whilst the current MEPC approach fails to do so as many of the new-built ships already satisfy the EEDI requirements. In addition, as the operating speed is a parameter that cannot be determined in the design phase (the design speed is only determined), slow-steaming or other operating practices are not accounted in the current MEPC approach. The proposed approach addresses this issue by using reference or representative operating profiles, which can be used for comparing the ship energy efficiency during the ship design phase and benchmarking the various design alternatives.

As stated in the introduction, the requirement for every new-built ship to obtain the International Energy Efficiency Certificate (IEE Certificate) is based on the constraint that the Attained EEDI does not exceed the Required EEDI. Such strict pass/fail approach might be convenient for the Administration (member states of MARPOL or classification societies), but has the drawback that it does not differentiate ships that are significantly better than the minimum requirement from those which barely pass the set threshold. Therefore, instead of applying a pass/fail criterion, it might be more appropriate to rate ships according to different energy efficiency performance categories. 


\section{CONCLUSION}

The aim of this paper was to propose an approach in the EEDI definition for bulk carriers which would provide a fair basis for the comparison of different ships and encourage the application of innovative energy efficient technologies. This was done by modifying the Attained EEDI calculation in order to include multiple operating points (at different engine loads and at different ship operating conditions) and by modifying the Required EEDI by converting the EEDI reference line into the EEDI reference surface.

Drawbacks and limitations of the currently used methodology in the EEDI definition were detected and discussed. The current MEPC approach proclaims that it encourages the implementation of innovative energy efficient technologies. However, the EEDI requirement can be easily satisfied simply by the ship design speed reduction. The speed reduction increases the risk of ship under-powering and reduces the role of innovative energy efficient technologies. In the proposed approach developed in the present study, possible risks of ship under-powering due to the EEDI requirement are greatly reduced, since ships cannot satisfy the requirement simply by reducing the design speed. As a result, alternative methods to increase ship energy efficiency will be required to be considered during the ship design phase, which promotes the implementation of innovative energy efficient technologies on a greater scale. Most importantly, it was demonstrated that the proposed approach provides a fair basis for the comparison of energy efficiency of different bulk carriers, since the coefficient of determination in the proposed approach was 0.9576.

In addition, it would be more appropriate to rank ships based on various energy efficiency performance categories, instead of applying a pass/fail criterion. Similar approaches are already in effect in many other industries (from household appliances, buildings etc.) and thus, it seems reasonable to analyse the impact of its implementation for ships in a future research effort.

\section{ACKNOWLEDGMENTS}

This research was supported by the European Social Fund and the Croatian Ministry of Science, Education and Sport within the operational Programme Human Resources Development (Grant No. HR.3.2.01 -0030).

\section{References}


Ancic, I., Sestan, A. 2015 Influence of the required EEDI reduction factor on the $\mathrm{CO}_{2}$ emission from bulk carriers, Energy Policy 84, 107-116

Ancic, I., Sestan, A., Vladimir, N., Klisaric, V. 2014 Influence of new power sources on the Attained EEDI, Proceedings of the International Conference on Influence of EEDI on Ship Design, London, UK, $121-126$

Baldi, F., Theotokatos, G., Andersson, K. 2015 Development of a combined mean value-zero dimensional model and application for a large marine four-stroke Diesel engine simulation, Applied Energy $154,402-415$

Bøckmann, E., Steen, S. 2016 Calculation of EEDlweather for a general cargo vessel, Ocean Engineering 122, 68-73

Bengston, S., Fridell, E., Andersson, K. 2012 Environmental assessment of two pathways towards the use of biofuels in shipping, Energy Policy 44, 451-463

Blanco-Davis, E., Zhou P. 2016 Life Cycle Assessment as a complementarity utility ot regulatory measures of shipping energy efficiency, Ocean Engineering 128, 94-104

Butterworth, J., Atlar, M., Shi, W. 2015 Experimental analysis of an air cavity concept applied on a ship hull to improve the hull resistance, Ocean Engineering 110, 2-10

Calleya, A., Pawling, R., Greig, A. 2015 Ship impact model for technical assessment and selection of Carbon dioxide Reducing Technologies (CRTs), Ocean Engineering 97, 82-89

Cichowicz, J., Theotokatos, G., Vassalos, D., 2015. Dynamic energy modelling for ship life-cycle performance assessment. Ocean Engineering, 110(B), 49-61

Dedes, E. K., Hudson, D. A., Turnock, S. R. 2012 Assessing the potential of hybrid energy technology to reduce exhaust emissions from global shipping, Energy Policy 40, 204-218

Ekanem Attah, E., Bucknall, R. 2015 An analysis of the energy efficiency of LNG ships powering options using the EEDI, Ocean Engineering 110, 62-74

Guan, C., Theotokatos, G., Zhou, P., Chen, H. 2014, Computational investigation of a large containership propulsion engine operation at slow steaming conditions, Applied Energy 130, 370-383 
Kim, J.-H., Choi, J.-E., Choi, B.-J., Chung, S.-H. 2014 Twisted rudder for reducing fuel-oil consumption, Int. J. Nav. Archit. Ocean Eng. 6, 715-722

Livanos, G.A., Theotokatos, G, Pagonis D-N, 2014. Techno-economic investigation of alternative propulsion plants for Ferries and RoRo ships, Energy Conversion and Management, 79, 640-651

Mäkiharju, S.A., Perlin, M., Ceccio, S.L., 2012. On the energy economics of air lubrication drag reduction. Int. J. Naval Archit. Ocean Eng. 4 (4), 412-422

MEPC 2010 Full report of the work undertaken by the Expert Group on Feasibility Study and Impact Assessment of possible Market-based Measures, MEPC 61/INF.2, London, UK

MEPC 2011a Amendments to the Annex of the Protocol of 1997 to Amend the International Convention for the Prevention of Pollution from Ships, as Modified by the Protocol of 1978 Relating Thereto, Resolution MEPC.203(62), London, UK

MEPC 2008 Amendments to the Technical Code on Control of Emission of Nitrogen Oxies from Marine Diesel Engines, Resolution MEPC.177(58), London, UK

MEPC 2011b Marginal Abatement Costs and Cost Effectiveness of Energy-Efficiency Measures, MEPC 62/INF.7, London, UK

MEPC 2013 Guidelines for Calculation of Reference Lines for Use with the Energy Efficiency Design Index (EEDI), Resolution.231(65), London, UK

MEPC 20142014 Guidelines on the Method of Calculation of the Attained Energy Efficiency Design Index (EEDI) for New Ships, Resolution MEPC.245(66), London, UK

MEPC 2016 Report of the Correspondence Group on EEDI review required under regulation 21.6 of MARPOL Anex VI, MEPC 70/5/15, London, UK, August, 2016.

Miola, A., Marra, M., Ciuffo, B. 2011 Designing a climate change policy for the international maritime transport sector: Market-based measures and technological options for global and regional policy actions, Energy Policy 39, 5490-5498

Rehmatulla, N., Smith, T. 2015 Barriers to energy efficiency in shipping: A triangulated approach to investigate the principal agent problem, Energy Policy 84, 44-57 
Runko Luttenberger, L., Ancic, I., Sestan, A., 2013. The viability of short-sea shipping in Croatia, Brodogradnja 64 (4), 472-481

Simic, A. 2014 Energy Efficiency of Inland Waterway Self-Propelled Cargo Ships, Proceedings of the International Conference on Influence of EEDI on Ship Design, London, UK, 49-57

Thomson, H., Corbett, J. J., Winebrake, J. J. natural gas as a marine fuel, Energy Policy 87, 153-167 


\title{
Towards Improving Energy Efficiency Regulations of Bulk Carriers
}

\author{
Ivica Ančić ${ }^{* 1}$, Gerasimos Theotokatos ${ }^{2}$, Nikola Vladimir ${ }^{1}$ \\ ${ }^{1}$ University of Zagreb, Faculty of Mechanical Engineering and Naval Architecture, \\ Zagreb, Croatia, ivica.ancic@fsb.hr \\ ${ }^{2}$ University of Strathclyde, Department of Naval Architecture, Ocean and Marine \\ Engineering, Maritime Safety Research Centre, Henry Dyer Building, 100 Montrose \\ Street, Glasgow, G4 OLZ, United Kingdom
}

\begin{abstract}
The introduction of the Energy Efficiency Design Index (EEDI) by the International Maritime Organization (IMO) caused an upsurge in activities for increasing the energy efficiency and reducing the $\mathrm{CO}_{2}$ emissions of the new vessel designs. However, the application of the EEDI is not expected to further advance future design improvements partly owing to the fact the majority of the newbuildings already comply with EEDI requirements and particularly since EEDI only considers a single operating point. In addition, the EEDI does not effectively assess a realistic improvement of measures for increasing the ship operating energy efficiency as they can be quite effective in the considered operating point for the EEDI but their performance greatly varies in the real operating conditions. In this study, a more realistic definition of the EEDI is proposed, which is based on a number of representative vessel operating points. In this respect, one of the main flaws of the EEDI can be avoided, converting the EEDI in an index representing the actual ship operation. The application of the proposed approach for the case of bulk carriers is investigated and the results are discussed in order to reveal its advantages against the currently used approach. The proposed approach can be employed by IMO for improving the energy efficiency regulatory framework.
\end{abstract}

Keywords: EEDI, energy efficiency, bulk carriers, $\mathrm{CO}_{2}$ emission, EEDI reference surface 


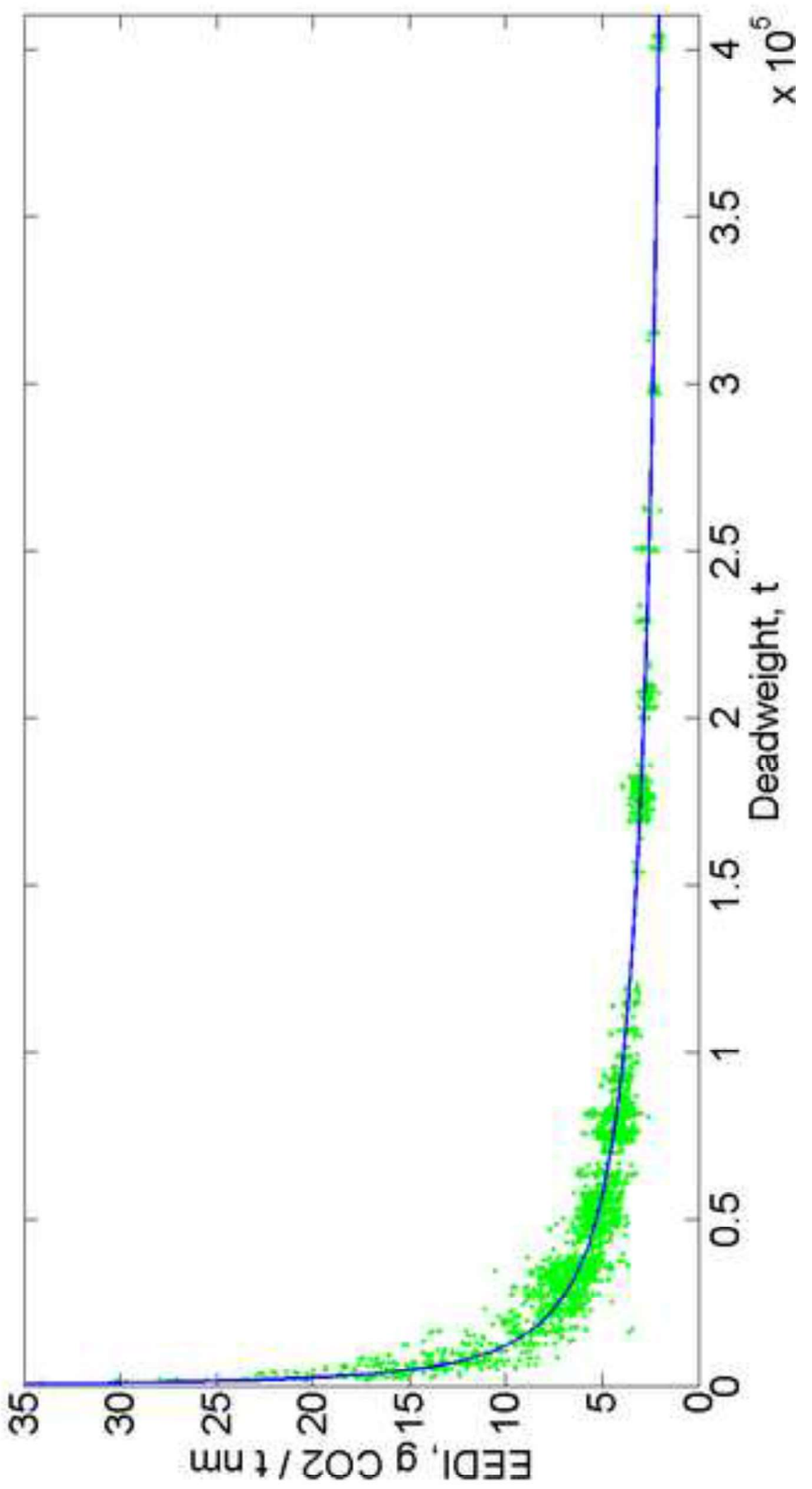




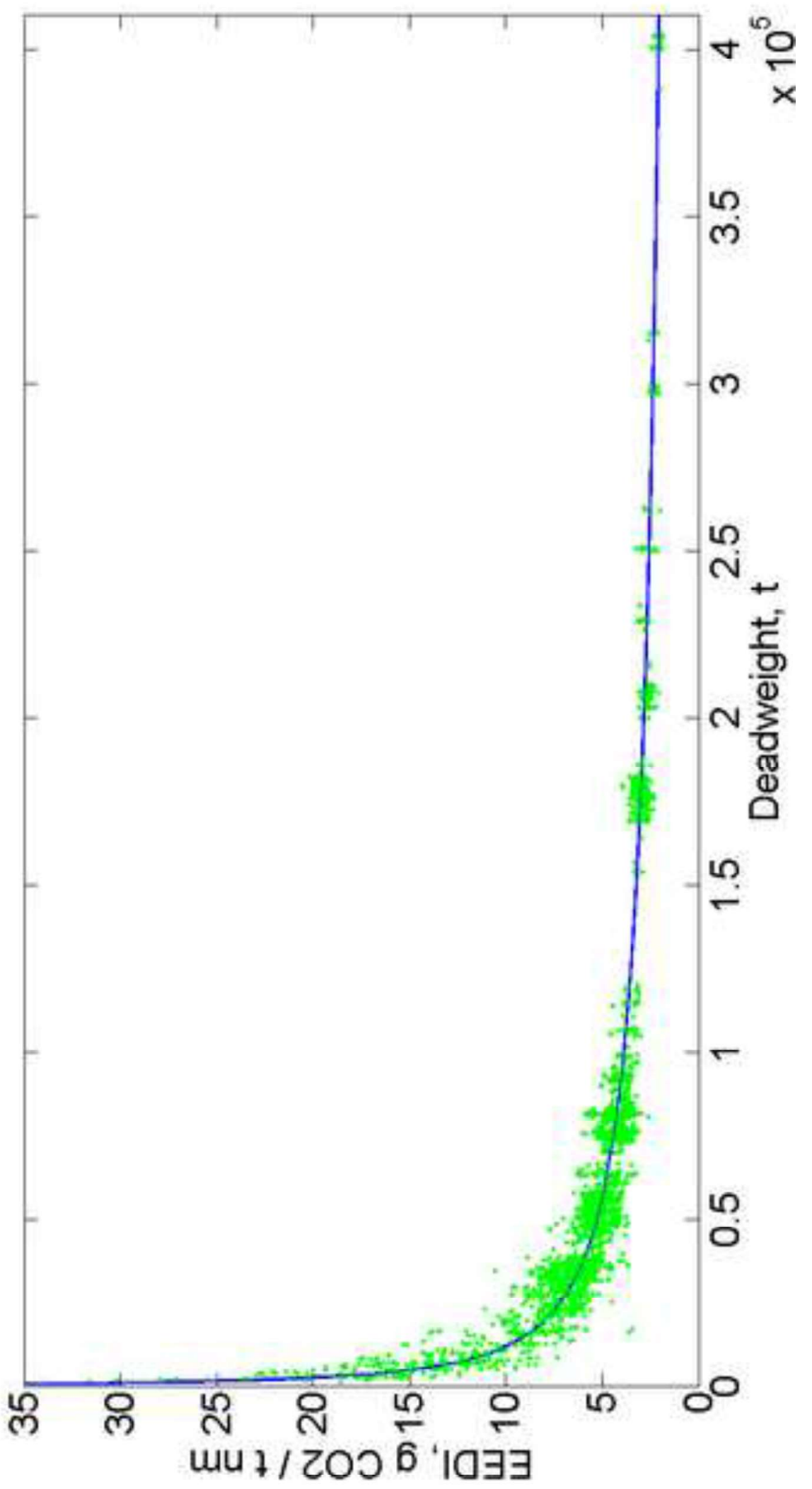













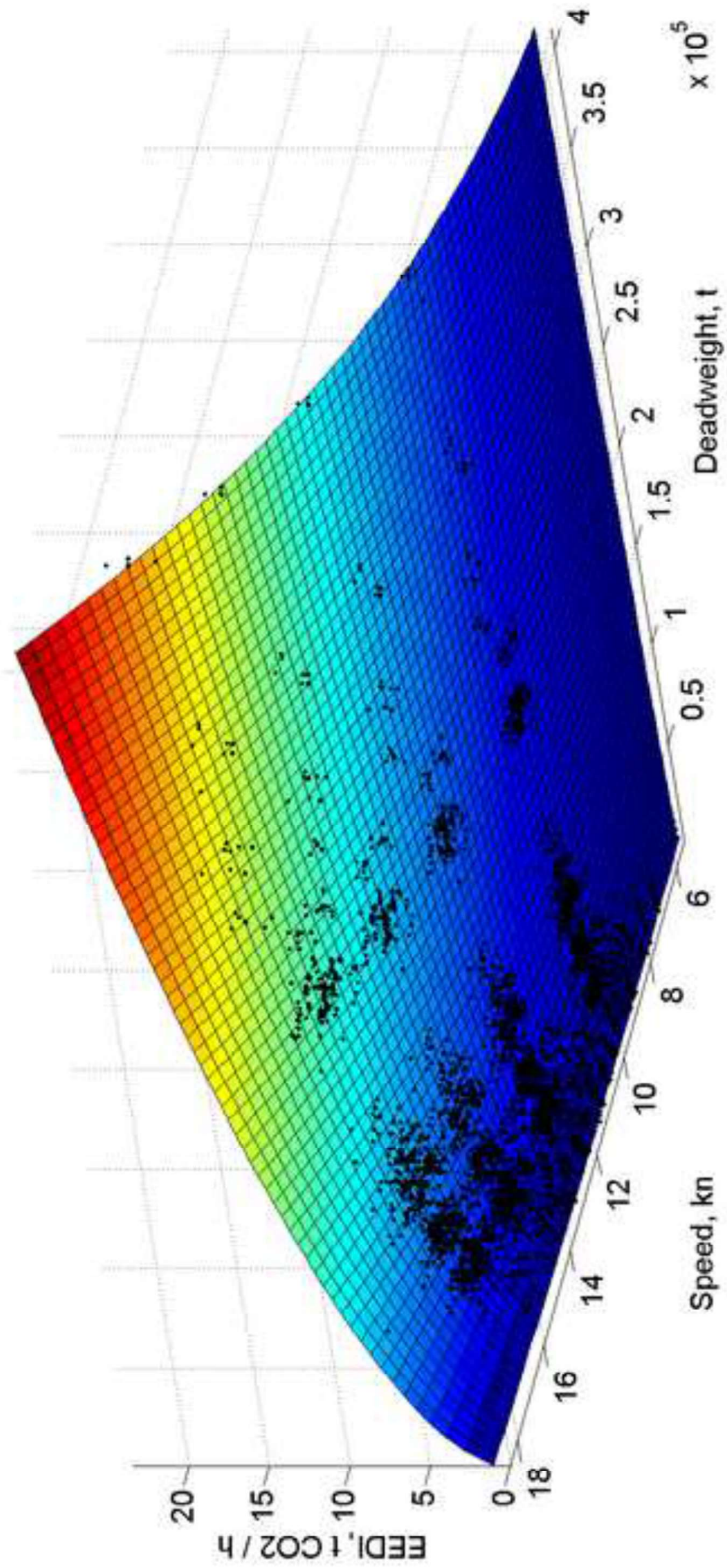




\section{Energy Efficiency of Bulk Carriers}

Ivica Ančić ${ }^{1}$, Gerasimos Theotokatos $^{2}$, Nikola Vladimir ${ }^{1}$

1University of Zagreb, CROATIA, ivica.ancic@fsb.hr

${ }^{2}$ University of Strathclyde, Glasgow, UK

Table 1 Weighting factors for various main engine operating loads for bulk carriers

\begin{tabular}{|l|c|c|c|c|}
\hline & $100 \%$ MCR & $75 \%$ MCR & $50 \%$ MCR & $25 \%$ MCR \\
\hline $\begin{array}{l}\text { NO }{ }_{x} \text { technical code E3 cycle } \\
\text { (MEPC, 2008) }\end{array}$ & 0.2 & 0.5 & 0.15 & 0.15 \\
\hline Banks et al. (2013) in 2009 & 0.1 & 0.5 & 0.3 & 0.1 \\
\hline Banks et al. (2013) in 2011 & 0.05 & 0.3 & 0.5 & 0.15 \\
\hline EEDI (MEPC, 2014) & 0 & 1 & 0 & 0 \\
\hline
\end{tabular}

Table 2 Engine and ship loading frequencies of occurrences for bulk carriers in operation

\begin{tabular}{|l|l|l|l|l|}
\hline \multirow{2}{*}{ Main engine } & Total & Laden & Ballast & In port \\
\cline { 2 - 5 } & 1 & $f_{x l}=0.4$ & $f_{x b}=0.3$ & $f_{x p}=0.3$ \\
\hline $100 \%$ & $f_{100 y}=0.07$ & $f_{100 l}=0.04$ & $f_{100 b}=0.03$ & $f_{100 p}=0$ \\
\hline $75 \%$ & $f_{75 y}=0.35$ & $f_{75 l}=0.2$ & $f_{75 b}=0.15$ & $f_{75 p}=0$ \\
\hline $50 \%$ & $f_{50 y}=0.21$ & $f_{50 l}=0.12$ & $f_{50 b}=0.09$ & $f_{50 p}=0$ \\
\hline $25 \%$ & $f_{25 y}=0.07$ & $f_{25 l}=0.04$ & $f_{25 b}=0.03$ & $f_{25 p}=0$ \\
\hline $0 \%$ & $f_{0 y}=0.3$ & $f_{01}=0$ & $f_{0 b}=0$ & $f_{0 p}=0.3$ \\
\hline
\end{tabular}


Table 3 Criteria to determine which bulk carriers are used for the EEDI reference line calculation

\begin{tabular}{|l|l|}
\hline Data source & IHS Fairplay Database - World Register of Ships (WROS) \\
\hline Ship size & 400 GT and above \\
\hline Delivery period & 1 January 1999 - 1 January 2009 \\
Ship type code & A21B2BC - Bulk carrier \\
& $\begin{array}{l}\text { A23A2BD - Bulk cargo carrier, self-discharging } \\
\text { A24A2BT - Cement carrier } \\
\text { A24B2BW - Wood chips carrier, self-unloading } \\
\text { A24C2BU - Urea carrier } \\
\text { A24D2BA - Aggregates carrier }\end{array}$ \\
\hline
\end{tabular}

Table 4 SFC values for different engine type and load (Baldi et al, 2015, Guan et al, 2014)

\begin{tabular}{|l|c|c|c|c|}
\hline Engine type/load & $100 \%$ MCR & $75 \%$ MCR & $50 \%$ MCR & $25 \%$ MCR \\
\hline Slow-speed $(<300 \mathrm{rpm})$ & 185 & 180 & 185 & 195 \\
\hline Medium-speed $(300<N<1400$ & 200 & 195 & 200 & 210 \\
rpm) & 220 & 215 & 220 & 230 \\
\hline High-speed $(>1400 \mathrm{rpm})$ & & & & \\
\hline
\end{tabular}


Table 5 Values of parameters $a$ and $c$ and the coefficient of determination for the EEDI reference line for bulk carriers

\begin{tabular}{|c|c|c|c|c|c|c|}
\hline \multirow[t]{3}{*}{ Date } & \multicolumn{3}{|c|}{1 Jan 1999 - 1 Jan 2009} & \multirow{2}{*}{\multicolumn{3}{|c|}{$\begin{array}{c}15 \text { Aug } 2000 \text { - } 15 \text { Aug } 2015 \\
\text { Updated calculation (SD defined in } \\
\text { "absolute" value) }\end{array}$}} \\
\hline & \multicolumn{2}{|c|}{ Repeated calculation } & \multirow[b]{2}{*}{ Adopted } & & & \\
\hline & $\begin{array}{c}\text { Before } \\
\text { correction }\end{array}$ & $\begin{array}{c}\text { After } \\
\text { correction }\end{array}$ & & $\begin{array}{c}\text { Before } \\
\text { correction }\end{array}$ & $\begin{array}{c}\text { After } \\
\text { correction, } \\
\text { "absolute" } S D\end{array}$ & $\begin{array}{c}\text { After } \\
\text { correction, } \\
\text { "relative" } S D\end{array}$ \\
\hline$a$ & 834.9 & 764.7 & 961.79 & 718.9 & 653.1 & 634.1 \\
\hline$C$ & -0.4666 & -0.4589 & -0.477 & -0.4537 & -0.4449 & -0.4428 \\
\hline$R^{2}$ & 0.8390 & 0.8972 & 0.9289 & 0.6881 & 0.8899 & 0.914 \\
\hline $\begin{array}{l}\text { No. of } \\
\text { ships } \\
\text { analyzed }\end{array}$ & 2,655 & 2,634 & 2,512 & 8,253 & 8,186 & 8,027 \\
\hline $\begin{array}{l}\text { No. of } \\
\text { ships } \\
\text { omitted }\end{array}$ & - & 21 & 16 & - & 67 & 226 \\
\hline
\end{tabular}

Table 6 Values of parameters $a, b, c$ and $d$ for the EEDI reference surface for bulk carriers

\begin{tabular}{|l|c|c|c|c|}
\hline Date & \multicolumn{4}{|c|}{15 Aug 2000 - 15 Aug 2015 } \\
\hline Approach & $\begin{array}{c}\text { Using only average values } \\
\text { of Estimated EEDI for a } \\
\text { ship }\end{array}$ & \multicolumn{2}{c|}{$\begin{array}{c}\text { Using every value of } \\
\text { Estimated EEDI for a ship }\end{array}$} \\
\hline & $\begin{array}{c}\text { Before } \\
\text { correction }\end{array}$ & $\begin{array}{c}\text { After } \\
\text { correction }\end{array}$ & $\begin{array}{c}\text { Before } \\
\text { correction }\end{array}$ & $\begin{array}{c}\text { After } \\
\text { correction }\end{array}$ \\
\hline$a$ & 17.39 & 460 & 4.4872 & 4.051 \\
\hline$b$ & 0.6305 & 0.5967 & 0.5563 & 0.5632 \\
\hline$c$ & 1.778 & 0.7248 & 2.818 & 2.824 \\
\hline$d$ & $4.698 \cdot 10^{5}$ & $2.692 \cdot 10^{5}$ & $3.181 \cdot 10^{5}$ & $3.221 \cdot 10^{5}$ \\
\hline$R^{2}$ & 0.927 & 0.9385 & 0.9499 & 0.9576 \\
\hline$S D$ & $14.44 \%$ & - & $15.35 \%$ & - \\
\hline $\begin{array}{l}\text { No. of } \\
\text { ships } \\
\text { analyzed }\end{array}$ & 8,253 & 7,925 & 8,253 & 7,950 \\
\hline $\begin{array}{l}\text { No. of } \\
\text { ships } \\
\text { omitted }\end{array}$ & - & 328 & & 303 \\
\hline
\end{tabular}

